\title{
Strengthening multi-hazards early warning system in the pacific through BMKG-UNESCAP collaboration pilot projects
}

\author{
Asteria S. Handayani ${ }^{1,}{ }^{*}$, Marjuki ${ }^{2}$, Agie Wandala Putra $^{3}$, Urip Haryoko ${ }^{4}$, Nurhayati ${ }^{5}$, Andi Eka Sakya ${ }^{6}$ \\ ${ }^{1}$ Research and Development Center, BMKG, Jl. Angkasa I No. 2, Kemayoran, Jakarta, 10720, Indonesia \\ ${ }^{2}$ Climate Services Center, BMKG, Jl. Angkasa I No. 2, Kemayoran, Jakarta, 10720, Indonesia \\ ${ }^{3}$ Public Weather Services Center, BMKG, Jl. Angkasa I No. 2, Kemayoran, Jakarta, 10720, Indonesia \\ ${ }^{4}$ Research and Development Center, BMKG, Jl. Angkasa I No. 2, Kemayoran, Jakarta, 10720, Indonesia \\ ${ }^{5}$ Public Weather Services Center, BMKG, Jl. Angkasa I No. 2, Kemayoran, Jakarta, 10720, Indonesia \\ ${ }^{6}$ Weather Modification Technology Center, BPPT, Jl. Raya Puspiptek, Serpong, Banten, Indonesia
}

\begin{abstract}
On the period of September to December 2017, three pilot projects were implemented in Tonga, Papua New Guinea, and Solomon Islands aiming to strengthen the multi-hazards early warning system in the respective countries through close collaboration between the Indonesian Agency for Meteorology Climatology and Geophysics (BMKG) and United Nations Economic and Social Commission for Asia and the Pacific (UNESCAP). Main activities during the implementation phase were tailored based on gap analysis and risk assessments conducted beforehand. Thus, installation of high-resolution numerical weather, ocean wave, and climate prediction and forecasting tools were chosen to fill in the assessed gaps. These activities were incorporated with capacity building activities and high-level meetings with related stakeholders in disaster risk management using the concept of Fast-Leveraging-Easy-Economical-Sustain (FLEES). All three pilot projects had successfully proven to achieve their objectives by improving the capacities of National Meteorological Services in those three countries to produce multi-hazards early warning in higher resolution at a regional scale for disaster management in their respective countries.
\end{abstract}

\section{Introduction}

Tonga, Papua New Guinea, and Solomon are geographically located in the Pacific Ocean with multiple hazards lurking into the small islands of Pacific Island Countries. The region exposes to floods, cyclones, storm surges, and droughts as well as earthquakes, volcanic eruptions, and tsunamis [1]. Besides that, the threat from climate change has been observed through the decades as rising sea levels, intense storm, and changing of rainfall patterns. All were summarized in the World Risk Report 2016 and discussed in the ESCAP Committee on Disaster Risk Reduction Meeting in 2017 [2]. It was clear that disaster risk is outpacing resilience in Pacific region and regional cooperation is the way forward. As disasters have no borders then the actions taken should be on a regionally cooperative basis [3].

The extensive socio-economic impacts associated with these multi-hazards and availability of information relating to these factors are critical for risk assessment. The assessment is the foundation for the development of strategies for risk reduction strategies, policies, and planning. Improvement of the early warning system and the establishment of community resilience are among others must be considered in this risk assessment process [4].
Based on the gap analysis and assessment conducted beforehand in Fiji and Samoa, it was recognized that there are crucial challenges in terms of institutional and technical capacities in Multi-Hazards Early Warning System (MHEWS) in Pacific Region National Meteorological Services (NMSs). For example, the need to improve the capacity on forecasting (weather, ocean wave, drought) by implementing high-resolution Numerical Weather Prediction (NWP) - Ocean wave Forecast System - Drought Information System, implementation Common Alert Protocol (CAP) to develop warning delivery system, and paraphrasing technical terminology in their clear, unambiguous and simple warning []ㅡ. A general training of Multi-Hazards Risk Assessment and Early Warning System for Pacific Island Countries (PICs) for focal points of those countries was conducted in Citeko, Indonesia on July to August 2017 to answer those challenges [ㅁ].

Each participant for the training should be able to decide which hazard on the work plan with regard to its impact to a significant level towards their country. Focal points from the three selected BMKG-ESCAP pilot projects in Tonga, Papua New Guinea (PNG), and the Solomon Islands have drafted carefully the work plan with the specific focus on the most frequent hazard

* Corresponding author: tya.lazuardi@gmail.com 
occurs in their countries which are flood for both Tonga and Solomon Islands and drought for PNG. The reason behind these work plans were all based on the threat from the changing climate [7]. It was considered that there is a crucial need to monitor climate condition in PNG at various intervals such as monthly, quarterly, and annually [ㅇ]

Following the training, three pilot projects had been implemented in Tonga, Papua New Guinea, and the Solomon Islands on the period of September to December 2017. The training objectives were to improve and strengthen institutional and technical capacities and qualities of MHEWS within the Meteorological Services in those three countries. These projects were funded by the Government of Japan which are implemented under the close collaboration of Indonesian Agency for Meteorology Climatology and Geophysics (BMKG) and United Nations Economic and Social Commission for Asia and the Pacific (UN ESCAP) [9].

\section{Materials and methodology}

\subsection{Themes and methods}

Each pilot project was designed to enable the improvement of draft work plans with these following themes and methods:

a) Improving capacity and quality of operating multihazard early warning systems through implementation of MET services by customizing Numerical Weather Prediction (WRF) and CAP, as well as improve accessibility to warning with National Disaster Management Office (NDMO) and development of work plan on Capacity Building for Operating Multi-hazard Early Warning Systems in Tonga from 2017 - 2019.

b) Strengthening Multi-Hazard Risk Assessment and Early Warning Systems with Applications of Space and Geographic Information Systems in Papua New Guinea through implementation of Drought Monitoring System, On-site capacity building sessions on installing, running and managing drought monitoring system as an operational program for PNG National Weather Services (NWS) staff. There is also Focus Group Discussion with National Agriculture Research Institute (NARI) and National Disaster Center (NDC) to enhance the climate awareness for stakeholder.

c) Improving capacity and quality of operating multihazard early warning systems through improvement of meteorological services by building the backbone phase of Future Flood Forecast Early Warning System (FFEWS) in the Solomon Islands through implementation of high-resolution WRF and ocean wave modeling from the global scale to regional scale, CAP, and on-site capacity building session on weather and ocean wave modelling. There are also Managerial-level meeting with relevant stakeholders in flood hazard management and development of work plan on FFEWS.

\subsection{Participants}

Most participants in the pilot project countries were forecasters and managers in each NMSs and NDMOs respectively. BMKG experts served as trainers and Information Technology (IT) administrators for the MHEWS installation.

\section{Findings and challenges}

Despite of differences in the three pilot project countries, the implementation phase has shown distinct similarities in terms of multi-hazards risk management. It was identified that there are lacks of infrastructure to operate high-resolution weather, ocean wave, and climate modelling and observation data, such as server, forecasting tools, and equipment for early warning system; standard operating procedure to implement the CAP; allocated budget specifically for development of early warning system; human resources capacities and understanding of numerical weather and climate prediction. These findings became a challenge for BMKG experts to conduct the pilot projects milestones in the field since there was a limited time to accomplish the work.

Fast - Leveraging - Easy - Economical - Sustain (FLEES) general concept was introduced and utilized through the pilot projects phase to tackle the issues. This concept was invented by Dr. Andi EkaSakya, the President of the World Meteorological Organization (WMO) Regional Association V upon learning the gaps analysis and risk assessment report.

-Fast: the approach has to quickly enable to help to facilitate daily operations as to cope with the increasing frequency and magnitude scale of extreme events. The installation process took place around one week time using the available server, the SmartMet server in TMS and SIMS and RIMES server in PNG NWS.

-Leveraging: the new tools should rise to a better level of skill as compared with the existing one. In this regard, human resources capacities and understanding of numerical weather, ocean, and climate prediction and forecasting tools were increased/ better enhanced in the given time.

-Easy: application of new tools should be easily be facilitated so that hands-on training on the numerical weather and climate prediction were able to be delivered in an interactive and engaging manner with a studentcentered approach to enable participants to comprehend the material in the given time.

-Economical: implementation of the new methodology is unnecessarily required much additional investment and as far as possible optimizing the existing one. Accordingly, the whole implementation process was conducted with the available budget from UN ESCAP and with the available infrastructure.

- Sustain: to prevail the operational of new system, consideration of help-desk service on daily basis, either 
hands-on training or remotely is made available so that confidence level of participants in producing weather, climate, ocean wave, and drought information was increased in the given time, and national collaboration platform has been developed in each respective countries to support the sustainability of the work plan implementations.

\section{Key results}

\subsection{Pilot project in tonga}

During the implementation phase on 23 September to 4 October 2017, Tonga Meteorological Services - Weather Research Forecasting (TMS-WRF) or the weather research forecasting system in Tonga Meteorological Services has been successfully installed with improved representation of boundary layer clouds over Southeast Pacific, with the output from GFS global model were set to be automatically downloaded and downscaled from 0.25 degree to $7 \mathrm{~km}$ and $2.3 \mathrm{~km}$ (Figure 1). The output from TMS-WRF is now available on the display in the main website of TMS. The CAP system for dissemination of warning from TMS has been improved by making its Standard Operational Procedure to provide warning information. Since November 2017 TMS has made official weather observations for their respective countries (as shown in Figure 2).

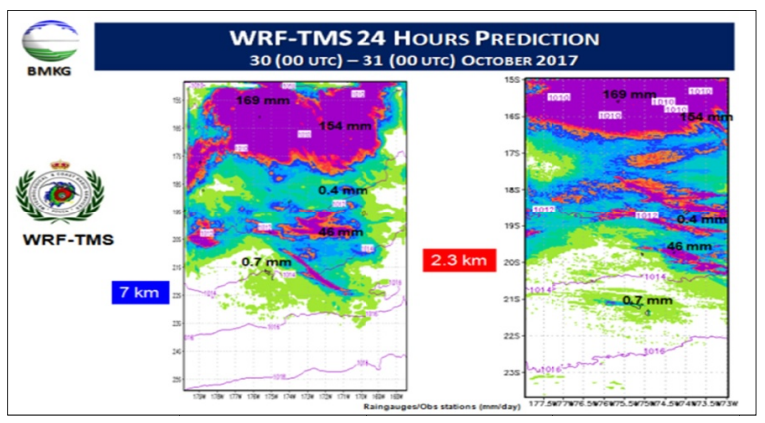

Fig. 1. WRF-TMS high-resolution prediction.

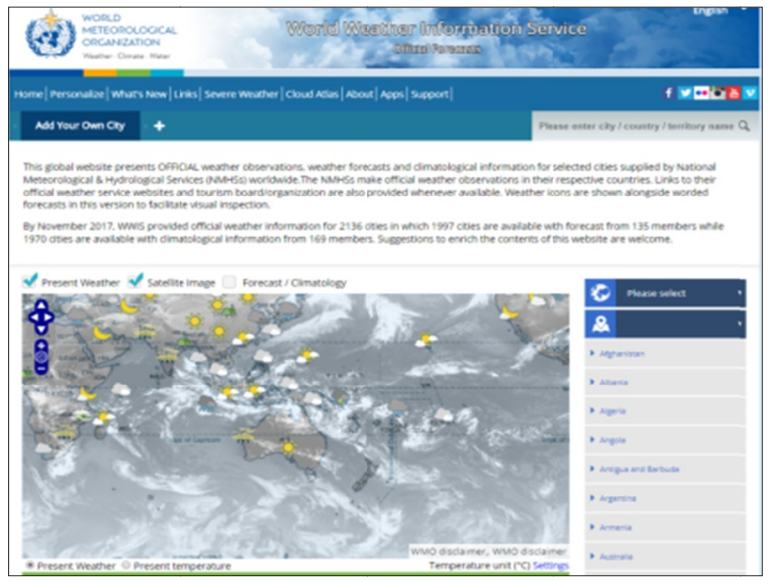

Fig. 2. WWIS Platform, TMS to global contribution.

\subsection{Pilot project in Papua new guinea}

During the implementation phase on 13 - 18 November 2017, the Drought Monitoring System has been successfully utilized in the PNG NWS using Regional Integrated Multi-hazard Early Warning System (RIMES)[10] server and customized software of Drought Monitoring Tools (DMT) for calculating Consecutive Dry Days (CDD), Dry Spell (DS) and Wet Spell (WS), Climate Prediction Tools (CPT) for calculating monthly and seasonal rainfall forecast, and Seasonal Climate Outlooks for Pacific Island Countries (SCOPIC) for monitoring drought using Standardized Precipitation Index (SPI) [11,12]. Focus Group Discussion held between stakeholders gave the recommendation to arrange a drought information operational procedure and initiate drought management plan. Further, the draft work plan has been improved with these recommendations.

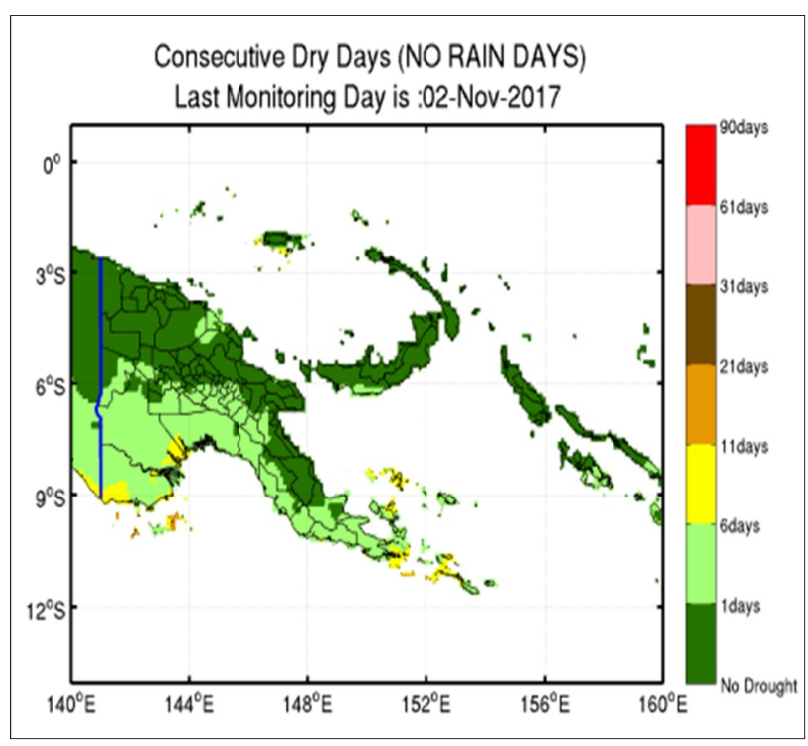

Fig. 3. Monitoring display of CDD in PNG by the PNG NWS.

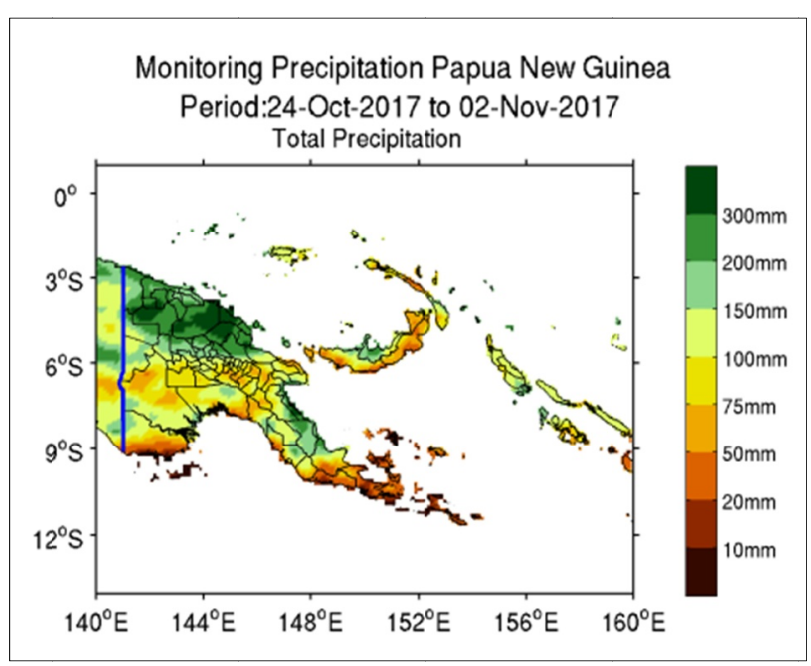

Fig. 4. Precipitation monitoring in PNG by the PNG NWS. 


\subsection{Pilot Project in the Solomon Islands}

During the implementation of the pilot project in the Solomon Islands on 12 - 19 December 2017, WRF and Wavewatch 3 as the weather and ocean wave modelling have been successfully installed using the SmartMet server and utilized with the domain of the whole region of Solomon Islands and resolution up to $7-\mathrm{km}$. Dissemination of warnings has come with the CAP as required by the WMO and registered to the Filter Alert Hub. With these new tools, Solomon Islands Meteorological Services (SIMS) can work in harmony with the Solomon Islands Disaster Management Division and the Solomon Islands Hydrology Office to build the FEWS in the next 5 years and provide better services and information to the public [13]. In addition, a conceptual model framework has also been introduced to equip the workforce by communicating their information to the public.

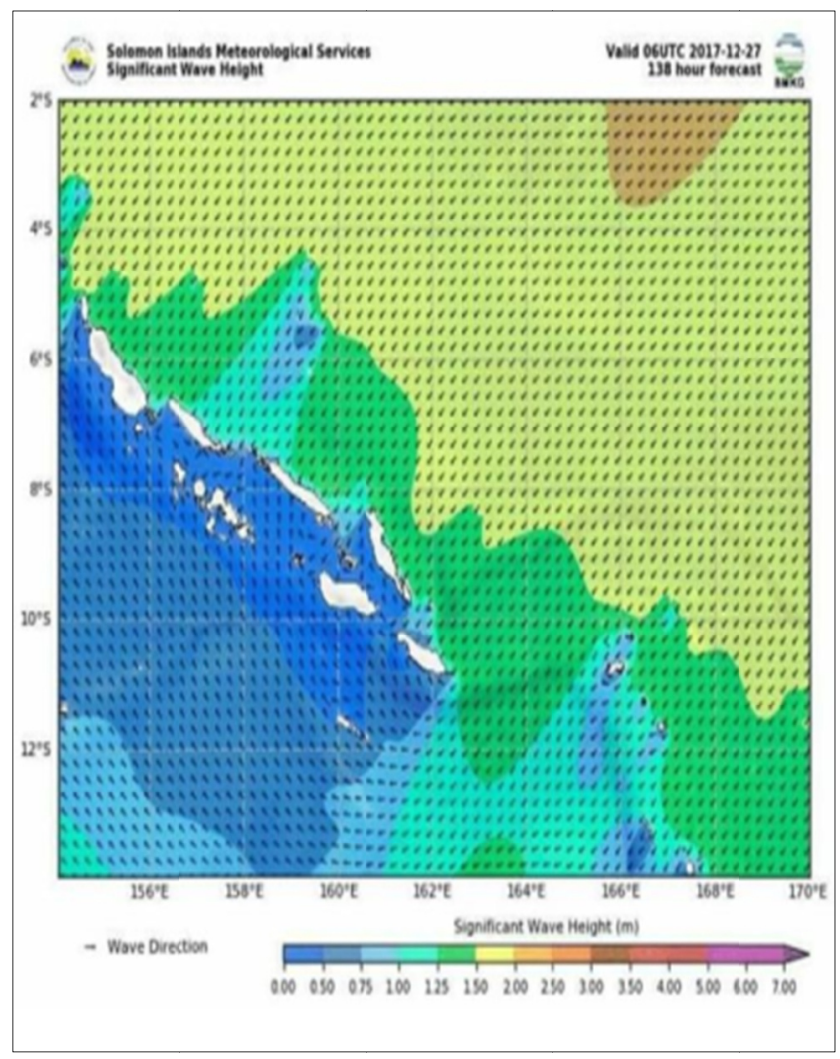

Fig. 5. Display of the SIMS' significant wave height information using Wavewatch3 output.

\section{Conclusions}

The three pilot projects have been made through the years from international donors to assist NMSs and NDMOs in the Pacific region with the capacities to provide weather-climate-earthquake information for their respective countries. However, there were still some identified gaps in institutional and technical capacities. The implementation of the three pilot projects in Tonga, PNG, and the Solomon Islands had filled those gaps by contextualizing and localizing early warning information at a regional scale for disaster management. Further, the three pilot projects have inspired the joint collaborations between related stakeholders in those countries to work and develop together a national work plan to tackle their natural hazards and disaster management issues.

FLEES general concept was successfully introduced by BMKG experts during the implementation period of the three pilot projects and had enabled the processes and achieved the outcomes as purposed. This concept could have successfully been adopted in developing a future strategy to be implemented in the PICs.

We gratefully acknowledge Prof. Ir. Dwikorita Karnawati, M.Sc, Ph.D. directive to allow us to implement the three pilot projects in Tonga, Papua New Guinea, and the Solomon Islands and for her continuous support and invaluable advises given to us through the whole projects. These projects were funded by the Government of Japan through BMKG-UN ESCAP collaboration for the Pacific Island Countries.

\section{References}

1. Hazard and Disaster Data in the Island Nation of Pacific.[Online]. Available: https://www.adb.org/features/hazard-and-disasterdata-island-nations-pacific (2014)

2. Shoring Up Early Warning System for Asia-Pacific SIDS[Online].Available:https://public.wmo.int/en/ media/news/shoring-early-warning-systems-asiapacific-sids (2018)

3. Asia Pacific Countries Boost Disaster Resilience Efforts in Regional UN Meeting [Online]. Available: $\quad$ http://www.unescap.org/news/asiapacific-countries-boost-disaster-resilience-effortsregional-un-meeting (2017)

4. S. Brown, Science for Humanitarian Emergencies and Resilience (SHEAR) Scoping Study, DOI: http://dx.doi.org/10.12774/eod cr.june2014.brown (2013)

5. D. Bertrand, and M. Shaffer Defining Hazards, Bull. Amer. Meteor. Soc., 98, No. 4, pp. 659-663, https://doi.org/10.1175/BAMS-D-15-00236.1 (2017)

6. "Capacity Development in Space Application and Geographic Information System, GP-STAR Factsheet", Bangkok, Thailand, (2017)

7. J.A. Otkins, et al., Facilitating the Use of Drought Early Warning Information through Interactions with Agricultural Stakeholders, Bull. Amer. Meteor. Soc., pp. 1073-1078, https://journals.ametsoc.org/doi/abs/10.1175/BAM S-D-14-00219.1

(2015)

8. K. Collins, et al., Stakeholder Coinquiries on Drought Impacts, Monitoring, and Early Warning System, Bull. Amer. Meteor. Soc., 97, No. 11, pp. ES217-ES220,

https://journals.ametsoc.org/doi/10.1175/BAMS-D16-0185.1 (2016)

9. K. Wang, Building Institutional Capacity for Multihazards Early Warning in Pacific Countries [Online]. Available: http://www.unescap.org/sites/default/files/Building 
$\% 20$ Institutional $\% 20$ Capacity $\% 20$ for $\% 20$ Multi-

Hazard\%20Early\%20Warning\%20in\%20Pacific\%2 0Countries\%2C\%20SAS.pdf (2018)

10. Multi-hazard Early Warning System Boosted in Pacific [Online]. Available: https://public.wmo.int/en/media/news/multihazard-early-warning-systems-boosted-pacific (2017)

11. E. Rakhmi Dewi, and A. Michael Whitbread, Use of Climate Forecast Information to manage Lowlands Rice-Based Cropping System in Jakenan, Central Java, Indonesia. Asian J. Agri. Res.,11: 6677, (2017)

12. Effective Climate Information Services for Agriculture in ASEAN: An ASEAN-CRN Knowledge Exchange Event to Increase Climate Resilience in ASEAN, Philippines, (2017)

13. "Emergency Risk Management for Health Fact Sheet", Climate Risk Management, World Health Organization, May (2013) 